\title{
Older siblings' influence on sexual behavior of high school adolescents in Mekelle, northern Ethiopia
}

This article was published in the following Dove Press journal: Adolescent Health, Medicine and Therapeutics

\author{
Mebrahtom Haftu \\ Haftu Berhe \\ Kinfe Tesfay \\ Martha Gebremeskel \\ College of Health Science, Mekelle \\ University, Mekelle, Ethiopia
}

Correspondence: Mebrahtom Haftu College of Health Science, Mekelle University, 187I Mekelle, Ethiopia,

Tel +25I 91 4042359

Email mebre.h@gmail.com
Background: Older siblings are one of the key sources of beliefs about sexual activity, including safe sexual practices, and can even exert pressure to engage in sexual activities. This effect persists beyond parental supervision and peer pressure. Despite this, although a considerable body of research has examined parental and peer influence, comparable data on older sibling influence on younger adolescent sexual behaviors are scant, and this area needs in-depth analysis.

Objective: The objective of this study was to assess older siblings' influence on sexual behavior of high school adolescents in Mekelle, northern Ethiopia in 2017-2018.

Methods: A cross-sectional study design was used, and a total of 285 adolescents who had ever had sex were sampled randomly from selected schools. Data were entered into Epi-info version 07 and exported to and analyzed with SPSS version 22. Means \pm SD, frequency, percentage, and cross-tabulation were used to describe the result. Bivariate and multivariate logistic regression was fitted to compute older sibling influence.

Results: Perceiving older sibling sexual behavior as risky increased adolescents' likelihood of engaging in risky sexual behavior. (AOR 4.52, 95\% CI 2.59-7.89) whereas high intimacy with an older sibling (AOR 0.32, 95\% CI 0.17-0.59) decreased the odds of risky sexual behavior (AOR 0.59, 95\% CI 0.30-0.92).

Conclusion: Older siblings had an influence on the sexual behavior of youngr adolescents. Perceiving older sibling sexual behavior as healthy and high sibling intimacy may serve as protective factors; however, risky sexual behavior of an older sibling can increase high school adolescents' likelihood for same. As such, families should realize that elders can affect their younger siblings' behavior, included the former in family strategies, and give them responsibility to protect their younger siblings.

Keywords: older siblings, influence, adolescent, sexual behaviors, Ethiopia

\section{Introduction}

Those aged 10-19 years are estimated to number 1.2 billion globally, about $20 \%$ of the world's population, and an estimated $82 \%$ of adolescents aged $\leq 19$ years live with at least one sibling, which is higher than those living in a household with a father (78\%). More than two-thirds of adolescents engage in sexual intercourse before age 19 years. . $^{1,2}$

Adolescent sexual behavior is not determined simply through sexual involvement. It is measured through direct markers of sexual behavior, such as age at first sex, consistent condom use, number of sexual partners, alcohol or substance 
use before sex, and pregnancy-prevention efforts. These behaviors have a direct effect on the future life of adolescents by possibly making them vulnerable to sexually transmitted diseases and unintended pregnancies or engaging in sexual behavior during adolescence. ${ }^{3}$

Scholars interested in adolescent sexual behavior have often focused on the role of family and friends as a reference group, suggesting that individuals actively use specific persons as references when they shape their own beliefs and behaviors. Older siblings are mostly trusted choices and a key element in transmitting beliefs about sexual activity and childbearing and providing information regarding sexual activities, including safe sexual practices, and even exerting pressure to engage in sexual activities. $^{4-6}$

Sibling similarities in sexual behaviors are greatest for same-sex siblings, similarity in age ( $<2$ years), if there is modeling, intimacy, and a warm relationship, and when siblings share friends. Beyond this, older siblings may play a matchmaker role, introducing their brothers and sisters to partners who are older and possibly more sexually experienced. This exposes the younger siblings to increased sexual risks, such as early sexual debt, having sex without enough knowledge on condom use and pregnancy protection, ormultiple sexual partners. ${ }^{7-9}$ Although studies agree on older siblings' influence, controversies exist as to whether the older sibling's role is positive or negative. ${ }^{4}$ The majority emphasize how older siblings' behaviors can negatively influence their younger siblings' sexual behaviors by exposing them to drugs and other substances that make them venerable to sexually transmitted infections and other diseases, such as HIV. On the other hand, some research has highlighted the positive role of sexually active older siblings in directing their younger siblings toward safe sexual practice by sharing with them lived experience on condom use and other pregnancy-prevention mechanisms. ${ }^{7,10}$

However, all existing studies on sibling effect have been conducted in US and Western nations, leaving a large gap in the literature about other world regions. In all sub-Saharan Africa, although a considerable body of research has examined parental and peer influences on adolescent behaviors, comparable data on sibling influence are more limited, as in Ethiopia. To address this gap, this study aimed to assess the role of older siblings and their influence on younger siblings' own sexual behaviors through their perceptions.

\section{Methods}

A school-based cross-sectional study was conducted among governmental and private high school students in Mekelle during March 1-30, 2017. All sexually active adolescents who had an older sibling in the selected eight high schools of northern Ethiopia within the academic calendar year 2017-2018 were the source of the population. Visually impaired students and those aged $>19$ years were excluded from the study. Questionnaires were completed after obtaining written consent/assent of the participants, attached to the questionnaire (from parents if aged $<18$ years).

\section{Data-collection tools and process}

To collect the data, a structured self-administered questionnaire was adapted from a youths sexual behavior-surveillance instrument, ${ }^{3}$ which enabled us identify direct markers of adolescents' and their older siblings' sexual behavior. To assess sibling modeling, communication, and intimacy, a tool was adapted from Whiteman et $\mathrm{al}^{11}$ and Blyth et $\mathrm{al}^{12}$ and some items were added from the Ethiopian Demographic Health Survey and after a review of relevant literature to assess sociodemographic and other variables. The content validity of the questionnaire was assured by experts, and the internal consistency of items with Likert scales was checked with Cronbach's $\alpha(>0.7)$ after conducting a pretest.

\section{Data processing, analysis, and interpretation}

Sexual behavior of school adolescents was the dependent variable. In this study, it was assessed based on adolescents response (yes $=1$ or no $=0$ ) to five items that are direct markers of adolescent sexual behavior: age at first sex, consistent condom use, number of sexual partners, alcohol or substance use before sex, and unintended-pregnancy prevention. Adolescents were categorized as "risky" if they affirmed any ofsexual intercourse before the age of 15 years, inconsistent condom use, multiple sexual partners, drug or substance use immediately before sex, and poor unintended pregnancy-prevention practices. If responses were negative to all five direct markers, they were considered to have healthy sexual behavior. ${ }^{3}$ Perceptions of older siblings' sexual activities were measured through yes/no answers to the five items assessing younger adolescents' perceptions of their older brother's/ sister's sexual engagement, age at first sex, condom use, 
number of sexual partners, drug or substance use before, sex and unintended pregnancy-prevention practices.

Independent variables were sibling characteristics (sex, age difference, and dyad type), and perception of older sibling's sexual activity, sibling's relationship quality (siblings' intimacy, modeling, and communication) were included. In this study, sibling intimacy was assessed through frequency of arguing and/or fighting with the older sibling, feelings of love toward the older sibling, and time spent with the older sibling. Six Likert-scale items with range from 1 (never) to 5 (very often) were used. Since the data were normally distributed (Shapiro-Wilk $P=0.62$ ), scores greater than the total mean on the relational intimacy scale were taken as intimacy with older siblings. ${ }^{12}$ In this study, sibling modeling was defined as the extent to which they tried to be like their sibling and their sibling encouraged them to participate in particular activities, as well as the degree to which their sibling set a positive example. Those with scores $>75 \%$ iover five items were considered to have high older-sibling modeling. ${ }^{11}$

Analysis was done with SPSS version22. To describe the statistics, frequencies, percentages, crosstabulation, and means \pm SD were used. Binary logistic regression was used to determine older siblings' influence on the sexual behavior of adolescents, and in the belief that significant factors other than the older sibling could affect the adolescent's sexual behavior, the screening value was increased, and those variables with $(P<0.3)$ were introduced to the multivariate logistic regression to control for confounders. Before inclusion of predictors in the final logistic regression model, the multicollinearity effect was checked using the variance-inflation factor and tolerance test and values were $<10$ and $>0.1$, respectively, which showed a low degree of correlation among independent variables. The Hosmer-Lemeshow goodness-of-fit statistic was used to check if data fit with the logistic model. AOR with $95 \%$ CI for those variables with $P<0.05$ was declared to show the level of association and statistical significance.

\section{Sample-size determination and sampling techniques}

The sample size was calculated using a single populationproportion formula by considering the proportion of older siblings' influence on the sexual behavior of adolescents as $50 \%, 5 \%$ margin of error, $95 \%$ confidence level, and total population (sexually active adolescents who had an older sibling adolescents) 1,089. The final sample was 285. To select study participants, multistage sampling was employed to enroll them from each selected high school and school grades. Students were selected through simple random sampling.

\section{Ethical considerations}

Ethical clearance was obtained from the Institutional Review Committee of Mekelle University College of Health Sciences, and an official letter of cooperation was written to the regional education bureau to get permission to conduct the study in the selected schools. Full written informed consent was obtained from participants aged $>18$ years, and for those aged $<18$ years, written consent was obtained from parents with assent from students. Privacy and strict confidentiality were maintained during the data-collection process. No personal details were recorded or produced in any documentation related to the study, and the information collected was anonymous and confidential. Issues like the absence of any direct benefit from participating in the study and risks following not participating in this study were included in the information sheet and declared during data collection.

\section{Results \\ Sociodemographic and behavioral characteristics of respondents}

More than half the study participants $(166,58.2 \%)$ were female. The mean age of respondents was $17 \pm 1.146$ (1419) years years. Those aged $\leq 15$ years had an increased proportion of risky sexuality $(92.3 \%)$ than those $>16$ years age $(45.1 \%)$. Of the study participants, $153(53.7 \%)$ were middle children and 160 (56.1\%) had pocket money. A total of $224(78.6 \%)$ respondents were living with both parents. Concerning personal characteristics, 87 (30.5\%) reported having viewed pornographic video or media. Among those, 47 (54\%) had risky sexual behavior. In sum, $103(36.1 \%)$ respondents reported having drunk alcohol and 46 (16.1\%) report having chewed khat (Table 1).

\section{Adolescents' sexual behavior}

A total of 285 adolescents who had had sex were included, and $108(37.9 \%)$ had had sex in the 3 months preceding the study. The most common reason for sexual engagement was "falling in love" 117 (41.1\%). Regarding adolescent sexual risk, only $156(54.7 \%)$ used condoms 
Table I Sociodemographic and behavioral characteristics of high school adolescents in Mekelle $(n=285), 2017-2018$

\begin{tabular}{|c|c|c|c|}
\hline & \multirow{2}{*}{$\begin{array}{l}\text { Frequency, } \\
\text { (\%) }\end{array}$} & \multicolumn{2}{|c|}{ Sexual behavior } \\
\hline & & $\begin{array}{l}\text { Healthy, } \\
\text { n (\%) }\end{array}$ & $\begin{array}{l}\text { Risky, } \\
\text { n (\%) }\end{array}$ \\
\hline \multicolumn{4}{|l|}{ Age } \\
\hline$\leq 15$ years & $26(9.1)$ & $2(7.7)$ & $24(92.3)$ \\
\hline$\geq 16$ years & $259(90.9)$ & $142(54.8)$ & $117(45.2)$ \\
\hline \multicolumn{4}{|l|}{ Sex } \\
\hline Male & $119(41.8)$ & $62(52.1)$ & 57 (47.9) \\
\hline Female & $166(58.2)$ & $82(49.4)$ & $84(50.6)$ \\
\hline \multicolumn{4}{|l|}{ Grade } \\
\hline 9 and 10 & $112(39.3)$ & $64(57.1)$ & $48(42.9)$ \\
\hline 11 and 12 & $173(60.7)$ & $80(46.2)$ & $93(53.8)$ \\
\hline \multicolumn{4}{|l|}{$\begin{array}{l}\text { Living } \\
\text { arrangements }\end{array}$} \\
\hline Both parents & $224(78.6)$ & III (49.6) & $113(50.4)$ \\
\hline One parent & $21(7.4)$ & $10(47.6)$ & II (52.4) \\
\hline Brother or sister & $15(5.3)$ & $9(60)$ & $6(40)$ \\
\hline Living alone & $25(8.8)$ & $14(56)$ & II (44) \\
\hline \multicolumn{4}{|l|}{ Birth position } \\
\hline First child & $93(32.6)$ & $42(45.2)$ & $51(54.8)$ \\
\hline Middle one & $153(53.7)$ & $80(52.3)$ & $73(47.7)$ \\
\hline Last child & $39(13.7)$ & $22(56.4)$ & $17(43.6)$ \\
\hline \multicolumn{4}{|l|}{ Pocket money } \\
\hline Yes & $160(56.1)$ & $76(47.5)$ & $84(52.5)$ \\
\hline No & $125(43.9)$ & $68(54.4)$ & $57(45.6)$ \\
\hline \multicolumn{4}{|l|}{ Alcohol use, ever } \\
\hline Yes & $103(36.1)$ & $56(54.4)$ & $47(45.6)$ \\
\hline No & 182 (63.9) & $88(48.4)$ & $94(51.6)$ \\
\hline \multicolumn{4}{|l|}{$\begin{array}{l}\text { Chewing khat, } \\
\text { ever }\end{array}$} \\
\hline Yes & $46(16.1)$ & $19(4 \mid .3)$ & 27 (58.7) \\
\hline No & 239 (83.9) & $125(52.3)$ & II 4 (47.7) \\
\hline \multicolumn{4}{|l|}{$\begin{array}{l}\text { Watching porno- } \\
\text { graphic video/ } \\
\text { media, ever }\end{array}$} \\
\hline Yes & $87(30.5)$ & $40(46)$ & $47(54)$ \\
\hline No & $198(69.5)$ & $104(52.5)$ & $94(47.5)$ \\
\hline
\end{tabular}

correctly and consistently in routine sexual practice, and those who had an older sibling practicing healthy sexual behavior scored higher $(87.8 \%)$ on condom use than adolescents with a risky elder (12.2\%). In total, 29 (10.2\%) had had more than four sexual partners, 125 (43.9\%) had a history of alcohol or substance use immediately before sexual intercourse, while only 79 (27.7\%) practiced pregnancy prevention strictly, with the mostly used mechanism being condoms $(123,46.3 \%)$. Overall, 141 (49.5\%, 95\% CI $44 \%-55 \%$ ) participants had risky sexual practices.

\section{Sibling characteristics}

Results on sibling characteristics showed that 164 $(57.5 \%)$ had an immediate older brother and 246 (73.7\%) had a sibling $>2$ years older. Concerning the sibling relationship, $140(49.1 \%)$ saw their older sibling as their model, and these participants showed decreased (43.6\%) exposure to risky sexual behavior compared to those who did not (55.2\%). Regarding sibling communication on sexuality-related issues, only 119 (41.8\%) reported having good communication with their older sibling. Results on sibling intimacy also showed that, $110(38.6 \%)$ participants perceived they were very close to their older siblings, and among these, only (29.1\%) had a lower proportion of risky sexual behavior compared to those who were not intimate with their elders (62.3\%; Table 2).

Table 2 Sibling characteristics and relationships among high school adolescents in Mekelle $(n=285), 2017-2018$

\begin{tabular}{|c|l|l|l|}
\hline & \multirow{2}{*}{$\begin{array}{l}\text { Frequency } \\
\text { (\%) }\end{array}$} & \multicolumn{2}{|l|}{ Sexual behavior } \\
\cline { 3 - 4 } & & $\begin{array}{l}\text { Healthy, } \\
\mathbf{n}(\%)\end{array}$ & $\begin{array}{l}\text { Risky, } \\
\mathbf{n}(\%)\end{array}$ \\
\hline $\begin{array}{c}\text { Older sibling's sex } \\
\text { Male } \\
\text { Female }\end{array}$ & $121(42.5)$ & $53(43.8)$ & $68(56.8)$ \\
\hline $\begin{array}{l}\text { Older sibling's } \\
\text { marital status } \\
\text { Married } \\
\text { Unmarried }\end{array}$ & $164(57.5)$ & $91(55.5)$ & $73(44.5)$ \\
\hline $\begin{array}{l}\text { Siblings' age } \\
\text { difference } \\
<2 \text { years } \\
>2 \text { years }\end{array}$ & $246(86.3)$ & $128(52.4)$ & $118(47.6)$ \\
\hline $\begin{array}{l}\text { Modeling } \\
\text { Set as model } \\
\text { Not set as model }\end{array}$ & $145(50.9)$ & $65(44.8)$ & $80(55.2)$ \\
\hline $\begin{array}{l}\text { Sibling } \\
\text { communication } \\
\text { Good } \\
\text { Poor }\end{array}$ & $210(73.7)$ & $102(48.6)$ & $108(51.4)$ \\
\hline $\begin{array}{l}\text { Intimacy } \\
\text { Intimate } \\
\text { Not intimate }\end{array}$ & $119(41.8)$ & $77(64.7)$ & $61(43.6)$ \\
\hline $166(58.2)$ & $67(40.4)$ & $80(55.2)$ \\
\hline
\end{tabular}




\section{Adolescents' perception of older siblings'} sexual behavior

Older sibling sexual behavior was assessed based on the adolescent's perception of their elders, and 278 (97.5\%) participants believed their older sibling had had sex before. A total of 225 (80.9\%) participants believed their older siblings had engaged in sexual activity after their 18 th birthday. Adolescents with early sexually engaged older siblings showed increased risky sexual behavior $(60.4 \%)$ over those with late sexually engaged older siblings (45.3\%). Regarding condom use, 237 (85.3\%) adolescents thought their older sibling used condoms consistently and $47(14.7 \%)$ perceive their older sibling as having had more than two sexual partners. Concerning pregnancy prevention, only $37(13.3 \%)$ participants believed their older siblings practiced contraception. Overall, 137 (48.1\%) adolescents thought their older sibling's sexual behavior was risky (Table 3 ).

\section{Older sibling's influence on adolescent's sexual behaviors}

To assess older sibling influence on younger adolescents' sexual behavior, older sibling sex, age difference between adolescents and older siblings, adolescent intimacy with their elders, adolescent modeling, perceived older sibling sexual behavior, and sibling-dyad type were introduced to the multivariate logistic regression model, since $P<0.3$ in bivariate analyses. Finally, adolescents' intimacy with their elders and perception of older siblings' sexual behavior showed a significant association with adolescent sexual behavior.

Adolescents who were intimated with older sibling were less likely have risky sexual behavior compared to those not intimate with their older sibling (AOR 0.32, 95\% CI $0.17-0.59 ; P<0.01$ ) (Table 4). The odds of adolescents who perceive their older siblings' sexual behavior as risky having risky sexual behavior themselves were 4.5 times higher than those who perceived their older sibling's sexual behavior as healthy (AOR 4.52, 95\% CI (2.59-7.89; $P<0.001$; Table 4).

\section{Discussion}

This study provides into risky and protective effects of older siblings on younger high school adolescents. Similarly to other studies done in the Western world, West Africa, and Kenya, ${ }^{13}$ this study also shows adolescents perceptions of their older siblings' sexual behaviors
Table 3 High school adolescents' perceptions of older siblings' sexual behavior, Mekelle 2017-2018

\begin{tabular}{|c|c|c|c|}
\hline & \multirow{2}{*}{$\begin{array}{l}\text { Frequency } \\
(\%)\end{array}$} & \multicolumn{2}{|c|}{ Sexual behavior } \\
\hline & & $\begin{array}{l}\text { Healthy, } \\
\text { n (\%) }\end{array}$ & $\begin{array}{l}\text { Risky, } \\
\text { n (\%) }\end{array}$ \\
\hline \multicolumn{4}{|c|}{$\begin{array}{l}\text { Older sibling sexu- } \\
\text { ally active }\end{array}$} \\
\hline Yes & $278(97.5)$ & | 44 (5 I.8) & I $34(48.2)$ \\
\hline No & $7(2.5)$ & $7(100)$ & 0 \\
\hline \multicolumn{4}{|c|}{$\begin{array}{l}\text { Older sibling's age } \\
\text { at sexual engage- } \\
\text { ment, years } \\
(n=278)\end{array}$} \\
\hline$<18$ & $53(19.1)$ & $21(39.6)$ & $32(60.4)$ \\
\hline$>18$ & $225(80.9)$ & $123(54.7)$ & $102(45.3)$ \\
\hline \multicolumn{4}{|l|}{$\begin{array}{l}\text { Older sibling's } \\
\text { condom use } \\
(n=278)\end{array}$} \\
\hline Consistent & $237(85.3)$ & $127(53.6)$ & $110(46.4)$ \\
\hline Not consistent & $4 \mid(14.7)$ & $17(4 \mid .5)$ & $24(58.5)$ \\
\hline \multicolumn{4}{|l|}{$\begin{array}{l}\text { Older sibling's } \\
\text { number of sexual } \\
\text { partners }(n=278)\end{array}$} \\
\hline One & $23 I(83.1)$ & $125(54.1)$ & $106(45.9)$ \\
\hline$>$ Two & $47(13.3)$ & $19(40.4)$ & $28(59.6)$ \\
\hline \multicolumn{4}{|l|}{$\begin{array}{l}\text { Older sibling has } \\
\text { prevented } \\
\text { unwanted preg- } \\
\text { nancy }(n=278)\end{array}$} \\
\hline Yes & $37(13.3)$ & $22(59.5)$ & $15(40.5)$ \\
\hline No & $24 \mid(86.7)$ & $122(50.6)$ & $119(49.4)$ \\
\hline \multicolumn{4}{|c|}{$\begin{array}{l}\text { Older sibling's sex- } \\
\text { ual behavior }\end{array}$} \\
\hline Risky & $137(48.1)$ & $40(29.2)$ & $97(70.8)$ \\
\hline Healthy & |48 (5।.9) & $104(70.3)$ & $44(29.7)$ \\
\hline
\end{tabular}

were related to their own sexual behaviors. Adolescents who viewed older sibling sexual behavior as risky showed an increased chance of risky sexual behavior (AOR 4.52, 95\% CI 2.59-7.89). This finding is consistent with prior research documenting similarity in sexual activities among siblings. ${ }^{13-15}$ This sibling similarity might be due to younger siblings observing their older siblings' behavior and sexual permissiveness and subsequently using this knowledge as a point of reference in shaping their own behavior. This result suggests that older siblings can play a more beneficial role in their younger siblings' lives and is consistent with social learning theory ${ }^{16}$ and previous 
Table 4 Binary logistic regression of factors influencing sexual behavior of high school adolescents in Mekelle, 2017-2018

\begin{tabular}{|c|c|c|c|c|}
\hline & \multicolumn{2}{|c|}{ Sexual behavior } & \multirow[t]{2}{*}{ COR $(95 \% \mathrm{Cl})$} & \multirow[t]{2}{*}{ AOR $(95 \% \mathrm{Cl})$} \\
\hline & Risky, n (\%) & Healthy, n (\%) & & \\
\hline \multicolumn{5}{|l|}{ Older sibling's sex } \\
\hline Male & $68(56.2)$ & $53(43.8)$ & $1.59(0.99-2.56)$ & $1.45(0.83-2.52)$ \\
\hline Female & $73(44.5)$ & $91(55.5)$ & 1 & 1 \\
\hline \multicolumn{5}{|l|}{ Age difference fromolder sibling } \\
\hline$\leq 2$ years & $33(44)$ & $42(56)$ & $0.74(0.43-1.26)$ & $1.14(0.61-0.13)$ \\
\hline$>2$ years & $108(51.4)$ & $102(48.6)$ & 1 & 1 \\
\hline \multicolumn{5}{|l|}{ Sibling dyad } \\
\hline Same sex & $64(45.1)$ & $78(54.9)$ & $0.70(0.44-1.12)$ & $0.91(0.53-1.56)$ \\
\hline Different sex & $77(53.8)$ & $66(46.2)$ & 1 & 1 \\
\hline \multicolumn{5}{|l|}{ Sibling intimacy } \\
\hline Yes & $32(29.1)$ & $78(70.9)$ & $0.24(0.14-0.4 I)$ & $0.32(0.17-0.59)^{* *}$ \\
\hline No & $109(62.3)$ & $66(37.7)$ & I & 1 \\
\hline \multicolumn{5}{|l|}{ Sibling modeling } \\
\hline Yes & $79(56.4)$ & $61(43.6)$ & $0.62(0.39-1.00)$ & $0.90(0.51-1.60)$ \\
\hline No & $65(44.8)$ & $80(55.2)$ & & 1 \\
\hline \multicolumn{5}{|l|}{ Perception of older sibling's sexual behavior } \\
\hline Risky & $40(29.2)$ & $97(70.8)$ & $5.73(3.44-9.54)$ & $4.52(2.59-7.89)^{* *}$ \\
\hline Healthy & $104(70.3)$ & $44(29.7)$ & 1 & 1 \\
\hline
\end{tabular}

Note: $* * P<0.001$.

sibling research, ${ }^{8,13,14}$ which suggests that indirect learning from an older sibling is one mechanism through which adolescents form expectations about health-risk behaviors, and strengthens the idea that older siblings can shape younger adolescents' sexual behaviors and potentially impact the transition to adulthood. However the odds were smaller than the data from Kenya (AOR 5.66, $95 \%$ CI 3.4-7.8), ${ }^{13}$ but higher than studies done in Rhode Island (AOR 3.72, 95\% CI 1.37-10.09), ${ }^{14}$ and Philadelphia (AOR 2.3, 95\% CI 1.27-3.55). ${ }^{15}$ This difference might be due to societal value differences among the study areas and possible variance in communication habits on sexuality-related issues with family members, particularly with older siblings.

Concerning relationship quality, adolescents who were intimate with their older siblings were less likely to have risky sexual behavior than those who were less intimate (AOR $0.32,95 \%$ CI $0.17-0.59$ ). This finding is in line with data from Mexico and the US. ${ }^{17,18}$ This might be due to the reason that positive relationship qualities, such as warmth and closeness with older siblings, providing the opportunity to discuss sexual issues freely and learn about important and protective behaviors from an older sibling. On the other hand, negative relationship qualities, such as rivalry, competition, and conflict, leave adolescents clueless on such issues, which might increase their likelihood for risky sexual behavior. The other most sited reason is older siblings being the most trusted information source. Close sibling interaction allows younger siblings to have easy access to trusted and accurate information on sexuality-related issues, which prevent them from involvement in risky sexual activity.

\section{Conclusion}

Findings from this study contribute to the pertinent literature, especially in magnifying the researcher's lens on possible predictors of adolescent sexual behavior. One in two sexually active adolescents engaged in risky sexual behavior, and perception of older siblings' sexual behavior and sibling intimacy were independent predictors of adolescent sexual behavior. Having a sexually at-risk older sibling and low sibling intimacy might increase adolescents' likelihood for risky sexual behavior. Families should realize that elders can affect younger adolescents' behavior,should be included in family strategies, and must give responsibility to elders to protect younger ones and enhance the sibling relationship, together with improving parent-youth connectedness and control. 


\section{Availability of data and materials}

All data and materials of this study are readily and openly available, and we are ready to hand these over upon request.

\section{Acknowledgments}

Our deepest gratitude goes to the School of Nursing, Health Sciences College, Mekelle University for proper review and approval of this paper. We would like to thank Mekelle school administration and students, data collectors, and study participants for their cooperation and assistance. Special thanks goes to staff members and friends for their unlimited contribution and support for the success of this paper. There was no funding for this research. All costs of data collection and analysis were covered by the authors.

\section{Author contributions}

All authors contributed to data analysis, drafting or revising the article, gave final approval of the version to be published, and agree to be accountable for all aspects of the work.

\section{Disclosure}

The authors report no conflicts of interest in this work.

\section{References}

1. Igras SM, Macieira M, Murphy E, Lundgren R. Investing in very young adolescents' sexual and reproductive health. Global Health. 2014;9(5):555-569.

2. Terry-Human E, Manlove J, Cottingham J. Worled trends and recent estimates: adolescent sexual activity. Child Trends. 2016.

3. Monica C, Chaney D, Chen W. Assessing specific sexual behavior: instrument development and validation techniques. Int $J$ Educ Social Sci. 2015;2(2):1-11.
4. Kirby D, Lepore G. Factors Affecting Teen Sexual Behavior, Pregnancy, ChildbearingAnd Sexually Transmitted Disease. New York: New Dir Child Adolesc Development; 2007.

5. Rodgers JL, Rowe DC, Harris DF. Siblings difference in adolescences sexual behaviour influnce prosses model. $J$ Marriage. 1992;54(1):142-152. doi:10.2307/353282

6. Schemit RL. The reference othe orentation. In: Carbodale, editor. An Extention of the Reference Group Concept. Carbondale, Illinois: Southernillinion University; 1972:401-432.

7. Sussan M, Hale M, Kimbrerly A, Whiteman SD. Adolescence siblings relationshipe and influnce. Marriage Family. 2012;1(74):913-930.

8. Widmer ED. Influence of older siblings on initiation of sexual intercourse. J Marriage Family. 2007;59(4):928-938. doi:10.2307/ 353793

9. Averett S, Argys L, Rees D. Older siblings and adolescent risky behavior: does parenting play a role? J Popul Econ. 2011;24 (3):957-978. doi:10.1007/s00148-009-0276-1

10. WidmerI E. Influence of older siblings on initiation of sexual intercourse. J Marriege Sex. 2010;59(2):928-938

11. Whiteman SD, Zeiders KH, Killoren SE, Rodriguez SA, Updegraff KA. Sibling influence on Mexican-origin adolescents' deviant and sexual risk behaviors: the role of sibling modeling. J Adolesc Health. 2014;54:587-592. doi:10.1016/j.jadohealth.2013.10.004

12. Blyth DA, Hill JP, Thiel KS. Item relational intimacy scale:sibling relationships during adolescence. Eur J Dev Psychol. 2005;2(3):253270. doi:10.1080/17405620544000002

13. Marston M, Beguy D, Kabiru C, Cleland J. Predictors of sexual debut among young adolescents in Nairobi's informal settlements. Int Perspect Sex Reprod Health. 2013;39(1):22-31. doi:10.1363/3902213

14. Almy B, Long K, Lobato D, Plante W, Kao B, Houck C. Perceptions of siblings' sexual activity predict sexual behavior among at-risk adolescents. $J$ Dev Behav Pediatr. 2015;36(4):258-266. doi:10.1097/DBP.0000000000000218

15. Cox RB, Shreffler KM, Merten, MJ, et al. Parenting, peers, and perceived norms: what predicts attitudes toward sex among early adolescents. $J$ Early Adolesc. 2015;35(1):30-53. doi:10.1177/ 0272431614523131

16. Bandura A. Social Learning Theory. Englewood Cliffs, NJ: Prentice Hall; 1977.

17. Kowal AK, Blinn-Pike L. Sibling influences on adolescents' attitudes toward safe sex practices. Fam Relat. 2004;53(4):377-384. doi:10.1111/fare.2004.53.issue-4

18. Eaest PL, Carol BA. Pregnacyt and parenting adolescents and their younger sisters: the influence of relationship qualities for younger sister outcomes. J Dev Behav Pediatr. 1997;18(2).
Adolescent Health, Medicine and Therapeutics

Publish your work in this journal

Adolescent Health, Medicine and Therapeutics is an international, peer-reviewed, open access journal focusing on health, pathology, and treatment issues specific to the adolescent age group. All aspects of health maintenance, preventative measures and disease treatment interventions are addressed within the journal and practitioners from all disciplines are invited to submit their work as well as healthcare researchers and patient support groups. The manuscript management system is completely online and includes a very quick and fair peerreview system. Visit http://www.dovepress.com/testimonials.php to read real quotes from published authors. 